\title{
Karbondioksitli Kaskad Soğutma Sistemlerinin Enerji Performans Değerlendirilmesi
}

\author{
Tuğba KOVACI ${ }^{1 *(D)}$ \\ ${ }^{1}$ Dr., Turkey
}

Geliş Tarihi/Received: 02.01.2020

Kabul Tarihi/Accepted: 24.01.2020
Doi: doi.org/10.31200/makuubd.669252

Araştırma Makalesi/Research Article

\section{ÖZET}

Bu çalışmada, R744 + R717 / R1234ze / R134a / R152a soğutkanları kullanılan dört farklı kaskad sisteminin karşılaştırılması sunulmuştur. Analiz $-45^{\circ} \mathrm{C}$ 'den $-20^{\circ} \mathrm{C}$ 'ye değişen farklı evaporatör sıcaklıklarında ve $30^{\circ} \mathrm{C}$ 'den $50^{\circ} \mathrm{C}$ 'ye değişen farklı kondenser sıcaklıklarında gerçekleştirilmiştir. Evaporatör sıcaklığı $25^{\circ} \mathrm{C}$ arttırıldığında, tüm sistemin soğutma performansı (COP $\left.{ }_{S Y S}\right)$ değeri yaklaşık \%60 ila \%64 arasında artmış ve kompresör gücü de

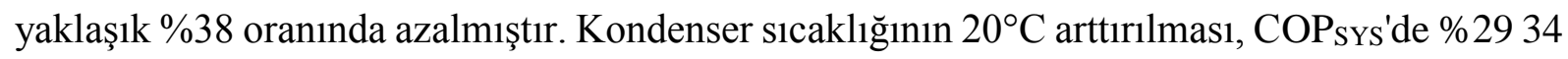
oranında bir azalmaya ve kompresör gücünde yaklaşık \%38-50 oranında bir artışa neden olmuştur. Sonuçlara göre, düşük küresel 1sınma potansiyeli (GWP) ve yüksek soğutma performansı değerine sahip olan R744/R717 soğutucu akışkanları kullanılan "sistem 1" kombinasyonunun, incelenen diğer kaskad soğutma sistemlerinden daha verimli olduğunu belirlenmiştir.

Anahtar kelimeler: Kaskad Soğutma, R744, COP.

\section{Energy Performance Assessment of $\mathrm{CO}_{2}$ Cascade Refrigeration Systems}

\section{ABSTRACT}

In this study, a comparison of the four different cascade systems using $\mathrm{R} 744+\mathrm{R} 717 / \mathrm{R} 1234 \mathrm{ze} / \mathrm{R} 134 \mathrm{a} / \mathrm{R} 152 \mathrm{a}$ refrigerant pairs has been presented. The analysis has been performed for different evaporator temperatures ranged from -45 up to $-20^{\circ} \mathrm{C}$, and different condenser temperatures ranged from 30 up to $50^{\circ} \mathrm{C}$. When the evaporator temperature has been increased by $25^{\circ} \mathrm{C}$, the system cooling performance (COP $\mathrm{CYS}_{\text {S }}$ value has increased by about $60 \%$ to $64 \%$, and the compressor work has decreased by about $38 \%$. Increasing the condenser

* Sorumlu yazar/Corresponding author

E-mail/e-ileti: tugbakovaci@gmail.com 
temperature by $20^{\circ} \mathrm{C}$ has resulted in a decrease in COPSYs of $29-34 \%$ and an increase in compressor work by about $38 \%$ to $50 \%$. According to the results, the combination of "system 1" using R744/R717 refrigerants which having low GWP and high cooling performance has been determined more efficient than other examined cascade refrigeration systems.

Keywords: Cascade Refrigeration, R744, COP.

\section{GİRIŞ}

Tek çevrimli bir buhar sıkıştırmalı soğutma sisteminin kullanımı sadece $-40 \mathrm{oC}$ civarında etkili bir soğutma sağlayabilir ve buharlaşma ile yoğunlaşma sıcaklıkları arasındaki büyük fark nedeniyle $-35^{\circ} \mathrm{C}$ 'nin altında verimlilik bozulmaya başlar. Bu nedenle daha düşük bir sıcaklığa ulaşmak için kademeli bir soğutma sistemi kullanmak gerekir. Kaskad soğutma sistemleri düşük sıcaklıkta (LTC) ve yüksek sıcaklıkta (HTC) bağımsız olarak çalışan iki kademeli soğutma sisteminden oluşur. İki soğutma sistemi, düşük sicaklık çevrimindeki kondenser tarafından serbest bırakılan sıcaklığın, yüksek sıcaklık çevriminde evaporatör tarafından emildiği bir ısı değiştirici ile birbirine bağlanır (Parmar ve Kapadia, 2015; Alhamid ve Syaka, 2010).

Yüksek bir soğutma performansı elde etmek için uygun bir soğutucu seçimi yapılmalıdır. Sınırlı enerji kaynakları, nüfus artışı ve dolayısıyla soğutma sistemlerine olan talebin artması ile soğutucu akışkan seçiminde, enerji ve maliyet tasarrufu yanında çevresel etkiler de önplana çıkmıştır (Boyaghchi ve Asgari, 2017). İyi termodinamik özellikleri nedeniyle CFC'ler yıllarca yaygın olarak kullanılmıştır. 20. yüzyılın sonlarında klor içeren soğutucu akışkanların atmosferdeki ozonun tükenmesi ile ilgili çevresel sorunlara neden oldukları belirlenmiştir. $\mathrm{Bu}$ soğutucu akışkanlara alternatif olarak HCFC ve HFC türü halokarbon soğutkanlar üretilmiştir, fakat bu soğutucu akışkanlar da küresel 1sınmaya katkıda bulunmuşlardır. İklim değişklikleri ve ozon krizi gibi sorunlarla birlikte soğutucu akışkanların seçiminde amonyak, karbon dioksit ve hidrokarbonlar gibi doğal soğutucu akışkanlara son zamanlarda ilgi artmıştır (Başaran ve Özgener, 2013, Aminyavari vd., 2014).

Farklı soğutkaların kullanıldığı kaskad soğutma sistemlerinin karşılaştırıldığı birçok çalışma vardır. Oruç vd. (2018) çalışmalarında yüksek GWP'ye sahip R404A ile düşük GWP'ye sahip R442A ve R453A soğutucularını deneysel olarak karşılaştırmıştır. Mancuhan vd. (2019) çalışmalarında kaskad sistemi için $\mathrm{R} 134 \mathrm{a} / \mathrm{CO}_{2}, \mathrm{R} 152 \mathrm{a} / \mathrm{CO}_{2}$ ve $\mathrm{NH} 3 / \mathrm{CO}_{2}$ sistemleri ile R134a/R404a, R152a/R404a ve NH3/R404a sistemlerinin olduğu iki durum için teorik bir 
model önermişlerdir. Singh ve Dasgupta (2016), soğutucu akışkan olarak R1234yf ve R744 kullanılan bir kaskad soğutma sisteminin termodinamik analizini yapmıştır. Dopazo vd. (2009), düşük ve yüksek sıcaklık çevrimlerinde çalışma sıvıları olarak $\mathrm{CO}_{2}$ ve $\mathrm{NH}_{3}$ kullanılan bir kaskad soğutma sisteminin analizini sunmuşlardır. Yilmaz vd. (2014) çalışmalarında düşük sıcaklık ve yüksek sıcaklık çevrimlerinde $\mathrm{CO}_{2}$ ve R404a soğutucu akışkanları kullanılan iki aşamalı kaskad soğutma sisteminin enerji ve ekserji analizini yapmışlardır. Mishra (2018) çalışmasında düşük sıcaklık çevriminde HFO-1234yf ve yüksek sıcaklık devresinde HFO1234ze alışkanları kullanılan kaskad soğutma sistemi için enerji ve ekserji analizi ile termodinamik performans değerlendirmesini sunmuştur.

Karbondioksit, kaskad soğutma sistemlerinin düşük sıcaklık devrelerinde en popüler ve en verimli çalışma akışkanı olarak ortaya çıkmaktadır. Karbondioksit, toksik olmayan, yanıcı olmayan, kolayca temin edilebilir, ucuz ve iklim dostu bir soğutucu akışkandır. Referans değeri 1 olan düşük küresel ısınma potansiyeli (GWP) endeksine ve sıfır ozon tükenme potansiyeli (ODP) endeksine sahip olan $\mathrm{CO}_{2}$, yüksek çalışma basıncı, düşük kritik sıcaklık ve düşük viskozite dahil olmak üzere kendine özgü termodinamik özellikleri nedeniyle, enerji açısından da büyük bir potansiyel sunmaktadır. Bununla birlikte, üçlü $\mathrm{CO}_{2}$ noktas1 - $56^{\circ} \mathrm{C}$ olduğundan, $85^{\circ} \mathrm{C}$ gibi düşük sıcaklıkların gerektiği çalışmalar için diğer soğutucu maddelerle (örneğin bir hidrokarbon) birlikte kullanılması gerekmektedir (Alhamid ve Syaka, 2010, da Silva vd., 2012, Messineo, 2012, Khanmohammadi vd., 2018).

Tablo 1. İlgili soğutucu akışkanların bazı fiziksel, çevresel ve güvenlik özellikleri

\begin{tabular}{|lcccc|}
\hline Soğutucu akışkan & Kritik basıç $[\mathrm{Mpa}]$ & Kritik sicaklık $\left[{ }^{\circ} \mathrm{C}\right]$ & ODP & GWP \\
\hline R744 $\left(\mathrm{CO}_{2}\right)$ & 7.37 & 31 & 0 & 1 \\
R1234ze & 3.63 & 109.4 & 0 & 7 \\
R134a & 4 & 101.1 & 0 & 1200 \\
R152a & 4.52 & 113.33 & 0 & 140 \\
R717 $\left(\mathrm{NH}_{3}\right)$ & 11.3 & 132.25 & 0 & 0 \\
\hline
\end{tabular}

Kaynak: Llopis vd., 2015, Lizarte vd., 2017, Y1lmaz ve Selbaş, 2017

$\mathrm{Bu}$ çalışmada düşük sıcaklık çevriminde soğutkan olarak $\mathrm{CO}_{2}$ (R744)'in kullanıldı̆̆g, yüksek sıcaklık çevriminde soğutkan olarak R717 ( $\left.\mathrm{NH}_{3}\right)$, R1234ze, R134a ve R152a akışkanlarının kullanıldığı kaskad soğutma sisteminde, çeşitli çalışma parametrelerinin soğutma performansı üzerindeki etkisi karşılaştırmalı olarak incelenmiştir. Seçilen soğutkanlar ve bazı özellikleri Tablo 1'de gösterilmektedir. 


\section{KASKAD BUHAR SIKIŞTIRMALI SOĞUTMA SİSTEMININ TERMODINAMIK MODELLENMESI}

\subsection{Sistem Modellemesi}

Bu çalışmada farklı soğutucu akışkanların kullanıldığı kaskad soğutma sistemleri modellenmiştir (Resim 1). Her soğutma sistemi bir kompresör, bir kondansatör, bir genleşme vanası ve bir buharlaştırıcıdan oluşmaktadır. İki çevrim, düşük sıcaklık çevrimi (LTC) için bir buharlaştırıcı ve yüksek sıcaklık çevrimi (HTC) için bir yoğunlaştırıcı olarak işlev gören, bir ısı değiştirici vasıtasıyla birbirlerine bağlanmaktadır. LTC buharlaştırıcısı, $\dot{Q}_{L}$ soğutma yükünü $T_{e}$ buharlaşma sıcaklığında emer. HTC yoğuşturucusu ise $\dot{Q}_{H} 1 S 1$ akışını $T_{c}$ yoğuşma sıcaklığında $\mathrm{T}_{\mathrm{o}}$ sıcaklığındaki ortama artmaktadır.

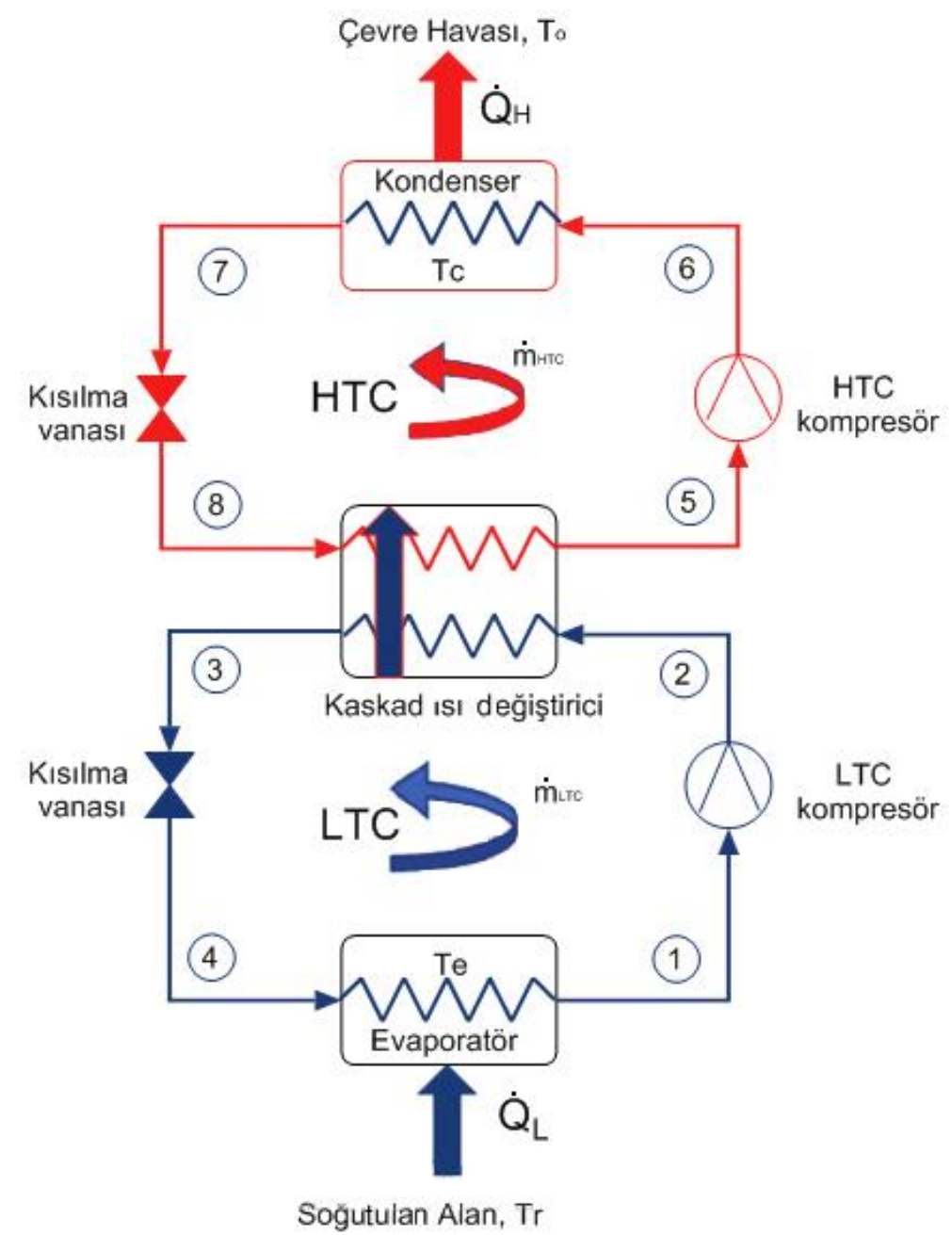

Şekil 1. Sisteminin şematik diyagramı 
Kaskad sistemi farklı akışkan çiftleri kullanılarak dört farklı durumda modellenmiştir. Sistem 1, 2, 3 ve 4 sirasıyla, R744/R717, R744/R1234ze, R744/R134a ve R744/R152a akışkan çiftlerinin kullanıldığı kaskad soğutma çevrimlerini temsil etmektedir (Tablo 2).

Tablo 2. Kaskad soğutucu akışkan çiftleri

\subsection{Enerji Analizi}

\begin{tabular}{|ccc|}
\hline & LTC & HTC \\
\cline { 2 - 3 } Sistem 1 & R744 & R717 \\
Sistem 2 & R744 & R1234ze \\
Sistem 3 & R744 & R134a \\
Sistem 4 & R744 & R152a \\
\hline
\end{tabular}

Çevrim modellenirken sabit akışlı enerji ve kütle denge denklemleri kullanılmıştır. Hesaplamayı kolaylaştırmak için analiz aşağıdaki genel varsayımlara dayandırılarak yapılmıştır.

- Borulardaki, kompresördeki veya sistem bileşenlerindeki basınç ve 1sı kayıpları/kazançları ihmal edilmiştir.

- Buharlaşma ve yoğuşma işlemleri izobariktir.

Tablo 3. Termodinamik analiz parametreleri

\begin{tabular}{|lcc|}
\hline Parametreler & Birim & Değer Aralığı \\
\hline Kondenser sıcaklığı & ${ }^{\circ} \mathrm{C}$ & 30 ile 50 \\
Evaporatör sıcaklığı & ${ }^{\circ} \mathrm{C}$ & -45 ile -20 \\
Soğutma kapasitesi & $\mathrm{kW}$ & 15 \\
\hline
\end{tabular}

Sistemdeki farklı akışkanların termodinamik özelliklerinin modellenmesi için Engineering Equation Solver (EES) yazılımı kullanılmıştır. Tablo 3'de her iki sistem için kullanılan temel giriş parametreleri verilmiştir. Genel kütle ve enerji denge deklemi Eşitlik 1 ve 2'de verilmiştir. Sistemin termodinamik analizinde herbir bileşen için kullanılan özel denklemler Tablo 4'te listelenmiştir.

$$
\begin{aligned}
& \sum_{\text {giren }} \dot{m}=\sum_{c ̧ l k a n} \dot{m} \\
& \dot{Q}-\dot{W}=\sum_{\text {çlkan }} \dot{m}-\sum_{\text {giren }} \dot{m}
\end{aligned}
$$


LTC, HTC ve tüm sistemin soğutma performanslarını belirlerken aşağıdaki eşitlikler kullanılmıştır:

LTC soğutma performansı: $C O P_{L T C}=\frac{Q_{s o g ̆ u t m a}}{\dot{W}_{k, L T C}}$
HTC soğutma performansı: $C O P_{H T C}=\frac{Q_{\text {soğutma }}}{\dot{W}_{k, H T C}}$

Tüm sistem soğutma performans1: $C O P_{s y s}=\frac{Q_{s o g ̆ u t m a}}{\dot{W}_{k, H T C}+\dot{W}_{k, L T C}}$

Tablo 4. Sistem bileşenleri için denge denklemleri

\begin{tabular}{|lll|}
\hline Değişkenler & Kütle & Kaskad enerji denklemleri \\
\hline HTC kompresör & $\dot{m}_{5}=\dot{m}_{6}$ & $\dot{W}_{k, H T C}=\dot{m}_{H T C}\left(h_{6}-h_{5}\right)$ \\
LTC kompresör & $\dot{m}_{1}=\dot{m}_{2}$ & $\dot{W}_{k, L T C}=\dot{m}_{L T C}\left(h_{2}-h_{1}\right)$ \\
Kondenser 1s1 transferi & $\dot{m}_{6}=\dot{m}_{7}$ & $\dot{Q}_{H}=\dot{m}_{H T C}\left(h_{7}-h_{6}\right)$ \\
Evaporatör 1s1 transferi & $\dot{m}_{1}=\dot{m}_{4}$ & $\dot{Q}_{L}=\dot{m}_{H T C}\left(h_{1}-h_{4}\right)$ \\
HTC ve LTC kisılma vanas1 & $\dot{m}_{3}=\dot{m}_{4}$ & $h_{3}=h_{4}$ \\
& $\dot{m}_{7}=\dot{m}_{8}$ & $h_{7}=h_{8}$ \\
Kaskad kondenseri & $\dot{m}_{2}=\dot{m}_{3}$ & $\dot{Q}_{c a s}=\dot{m}_{L T C} *\left(h_{3}-h_{2}\right)=\dot{m}_{H T C} *$ \\
& $\dot{m}_{5}=\dot{m}_{8}$ & $\left(h_{5}-h_{8}\right)$ \\
& & \\
& &
\end{tabular}

\section{BULGULAR}

Bu bölümde düşük sıcaklık çevriminde soğutkan olarak $\mathrm{CO}_{2}$ (R744)'in kullanıldığg1, yüksek sıcaklık çevriminde soğutkan olarak R717 ( $\left.\mathrm{NH}_{3}\right)$, R1234ze, R134a ve R152a akışkanlarının kullanıldığı kaskad soğutma çevrimlerindeki kondenser ve evaporatör sıcaklığının değişiminin, soğutma sisteminin performansına etkisi teorik olarak incelenmiştir. Modelleme için EES programı kullanılmıştır.

Evaporatör sıcaklığı $\left(\mathrm{T}_{\mathrm{e}}\right)$, soğutma çevrimi performansı üzerinde olumlu etkisi olabilecek ana parametrelerden biridir. Şekil 2, farklı soğutkanlar için evaporatör sıcaklığının $45^{\circ} \mathrm{C}$ ' den $-20^{\circ} \mathrm{C}^{\prime}$ ye arttırılmasının sistemin soğutma performansı (COPSYS) ve toplam iş girdisi $\left(\dot{\mathrm{W}}_{\mathrm{k}, S Y S}\right)$ üzerindeki etkisini göstermektedir. Evaporatör sıcaklığının artışı, tüm sistemlerde kompresör gücünün azalmasına, dolayısıyla performans artışına neden olmaktadır. Evaporatör sıcaklığının -45'den -20'ye arttırılması, sistem 1, 2, 3 ve 4 için sırasıyla, soğutma 
performansında $\% 63.4, \% 60.8, \% 61.2$ ve $\% 63$ 'l1k artışa ve kompresör gücünde $\% 38.8, \% 37.8$, \%37.9 ve \%38.6'l1k düşüşe neden olmuştur.

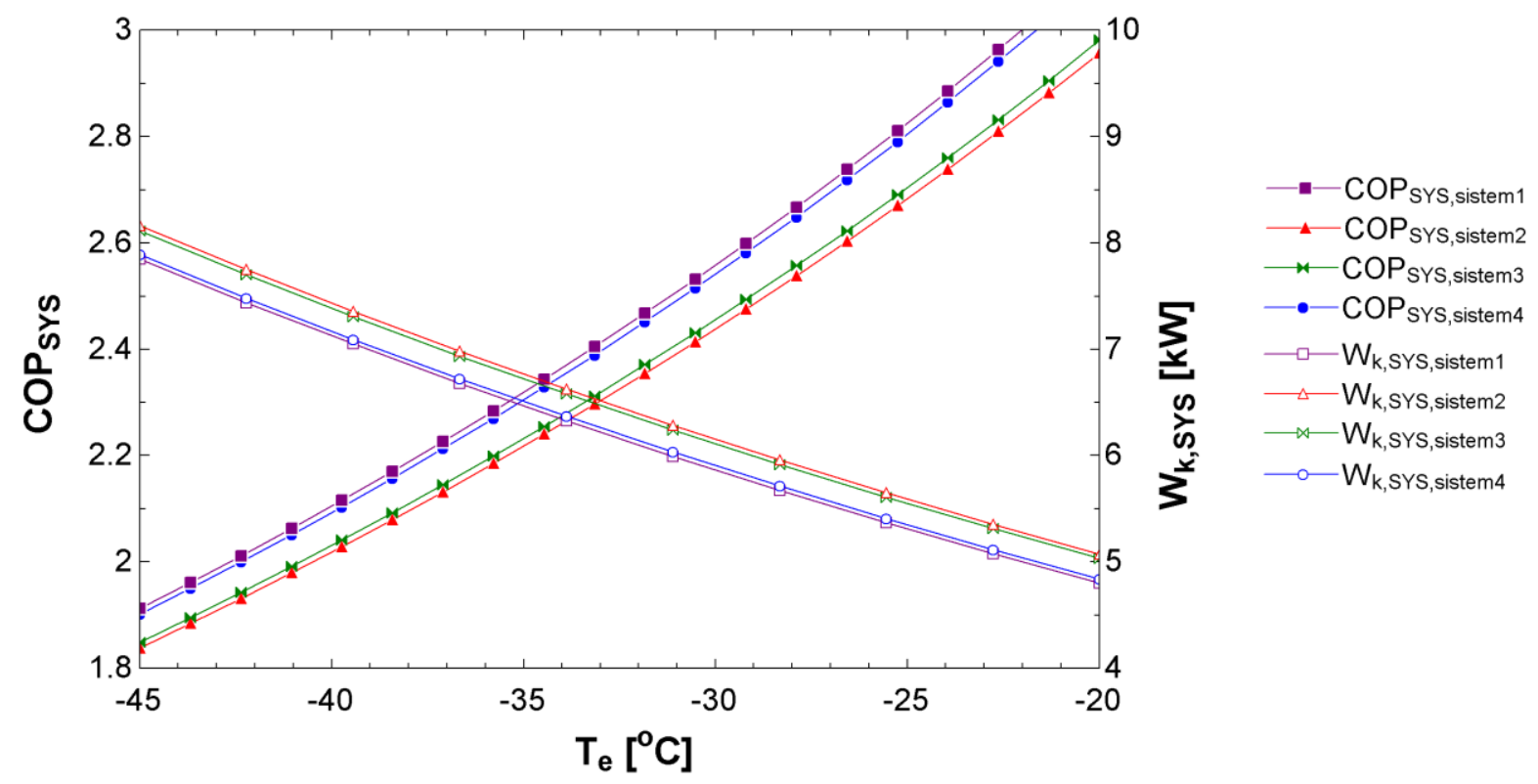

Şekil 2. Evaporatör sıcaklığı değişiminin COPSYs ve $\dot{\mathrm{W}}_{\mathrm{k}, \mathrm{SYS}}$ üzerindeki etkisi

Şekil 3, tüm sistemler için kondenser sıcaklığının soğutma performansı ve kompresör gücünün değişimine etkisini göstermektedir. Kondenser sıcaklığındaki artış, kompresör çıkış basıncındaki artış nedeniyle, kompresör gücünde artışa ve dolayısıyla soğutma performansında da düşüşe neden olmaktadır. Sıcaklığın $30^{\circ} \mathrm{C}^{\prime}$ dan $50^{\circ} \mathrm{C}$ 'e arttırılması, sistem 1, 2, 3 ve 4 için sirasıyla, $\% 29.2, \% 34.1, \% 33.3$ ve $\% 30.8$ 'lık soğutma performansı azalışına ve $\% 38.4, \% 49.4$, \%47.4 ve \%44.4'l1k kompresör gücü artışına neden olmuştur.

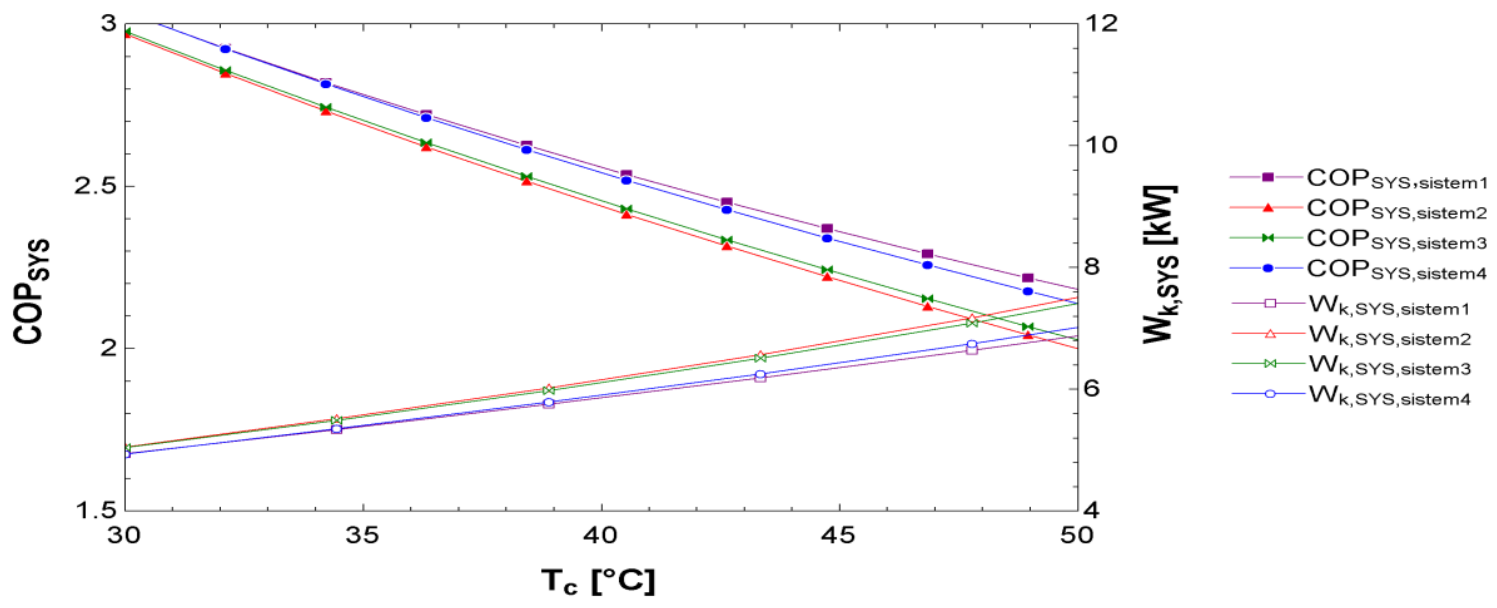

Şekil 3. Kondenser sıcaklı̆̆ı değişiminin COPSYs ve $\dot{W}_{k, S Y S}$ üzerindeki etkisi 
$-20^{\circ} \mathrm{C}$ ile $-45^{\circ} \mathrm{C}$ düşük buharlaşma sicaklık aralığında ve $30^{\circ} \mathrm{C}$ ile $50^{\circ} \mathrm{C}$ yüksek yoğuşma sıcaklık aralıklarında olan aynı termodinamik parametreler için sistem 1, diğer sistemlere göre daha yüksek performans göstermiştir. İkinci en yüksek performans değerleri sistem 4'de elde edilirken, bunu sırasıyla sistem 3 ve sistem 2 izlemiştir. Sistem 4'ün soğutma performansı ve kompresör gücü değerleri, sistem 1'e yakınken; sistem 2 ve sistem 3'deki akışkan çiftlerinin değerleri de birbirine yakındır. Tablo 5'de çevrimde kullanılan soğutucu akışkanların düşük sıcaklık ve yüksek sıcaklık çevrimlerindeki soğutma performansı, kütle ve kompresör gücü değerleri sayısal olarak verilmiştir.

Tablo 5. Farklı soğutucu akışkanların yüksek ve düşük sıcaklık çevrimlerindeki performansları

$$
\left(\mathrm{T}_{\mathrm{e}}=-30^{\circ} \mathrm{C}, \mathrm{T}_{\mathrm{c}}=40^{\circ} \mathrm{C}, \mathrm{Q}_{\mathrm{e}}=15 \mathrm{~kW}\right)
$$

\begin{tabular}{|cccccccc|}
\hline & $\mathrm{COP}_{\mathrm{SYS}}$ & $\mathrm{COP}_{\mathrm{HTC}}$ & $\mathrm{COP}_{\mathrm{LTC}}$ & $\begin{array}{c}\dot{\mathrm{m}}_{\mathrm{HTC}} \\
{[\mathrm{kg} / \mathrm{s}]}\end{array}$ & $\begin{array}{c}\dot{\mathrm{m}}_{\mathrm{LTC}} \\
{[\mathrm{kg} / \mathrm{s}]}\end{array}$ & $\begin{array}{c}\dot{\mathrm{W}}_{\mathrm{k}, \mathrm{HTC}} \\
{[\mathrm{kW}]}\end{array}$ & $\begin{array}{c}\dot{\mathrm{W}}_{\mathrm{k}, \mathrm{LTC}} \\
{[\mathrm{kW}]}\end{array}$ \\
\cline { 2 - 8 } Sistem 1 & 2.55 & 4.28 & 7.84 & 0.015 & 0.06 & 3.95 & 1.91 \\
Sistem 2 & 2.43 & 3.98 & 7.84 & 0.14 & 0.06 & 4.24 & 1.91 \\
Sistem 3 & 2.45 & 4.03 & 7.84 & 0.12 & 0.06 & 4.19 & 1.91 \\
Sistem 4 & 2.54 & 4.23 & 7.84 & 0.07 & 0.06 & 3.99 & 1.91 \\
\hline
\end{tabular}

\section{SONUÇLAR VE TARTIŞMA}

Farklı soğutkanlar kullanılarak modellenen dört farklı sistem için yapılan termodinamik analiz sonucunda elde edilen sonuçlar aşağıda listelenmiştir.

- Evaporatör sıcaklığındaki $25^{\circ} \mathrm{C}$ 'lik artış, \%60-64 arası performans artışına neden olurken, kompresör gücünde ortalama \%38'lik düşüşe neden olmuştur.

- Kondenser sıcaklığındaki $20^{\circ} \mathrm{C}^{\prime}$ lik artış, tüm sistemin soğutma performansı değerinde \%29 34 arasında düşüşe, kompresör gücünde ise \%38-50 arasında artışa neden olmuştur.

- Evaporatör sıcaklığının değişiminin tüm sistem ve düşük sıcaklık çevrimlerindeki soğutma performansı üzerinde, yüksek sıcaklık çevrimindekine kıyasla çok daha etkili olduğu görülmüştür. Evaporatör sıcaklığı değişiminin kompresör gücü üzerindeki etkisi de benzer şekilde, en fazla düşük sıcaklık çevriminde, daha sonra sırasıyla tüm sistem 
ve yüksek sıcaklık çevrimleri üzerinde olmuştur. Kondenser sıcaklığının değişiminin soğutma performansı ve kompresör gücü üzerindeki etkisi de evaporatör sicaklığı değişiminde elde edilen sonuçlara benzerdir.

Sonuçlara göre, incelenen farklı kaskad sistemleri içerisinde, sahip olduğu düşük GWP ve yüksek soğutma performansı değerleri nedeniyle, düşük sıcaklık çevriminde $\mathrm{CO}_{2}(\mathrm{R} 744)$ ve yüksek sıcaklık çevriminde $\mathrm{NH}_{3}$ (R717) soğutkanlarının kullanıldı̆̆ 1 sistem 1 kombinasyonu önerilmektedir.

\section{KISALTMALAR}

COP Soğutma performansı

h Entalpi, $\mathrm{kj} / \mathrm{kg}$

$\dot{m} \quad$ Kütle, $\mathrm{kg} / \mathrm{s}$

$\dot{\mathrm{Q}}_{\text {cas }} \quad$ Kaskad yoğuşturucusu isı transferi, $\mathrm{kW}$

$\dot{\mathrm{Q}}_{\mathrm{H}} \quad$ Kondenser 1s1 transferi, $\mathrm{kW}$

$\dot{\mathrm{Q}}_{\mathrm{L}} \quad$ Soğutma yükü, $\mathrm{kW}$

$\dot{\mathrm{Q}}_{\text {soğ }} \quad$ Soğutma kapasitesi, kW

$\mathrm{T}_{\mathrm{c}} \quad$ Yoğuşma sicaklığı, ${ }^{\circ} \mathrm{C}$

$\mathrm{T}_{\mathrm{e}} \quad$ Buharlaşma sıcaklığı,${ }^{\circ} \mathrm{C}$

$\mathrm{T}_{\mathrm{o}} \quad$ Ortam sicaklığ $1,{ }^{\circ} \mathrm{C}$

$\mathrm{T}_{\mathrm{r}} \quad$ Soğutulacak alan sıcaklığ $1,{ }^{\circ} \mathrm{C}$

$\dot{W}_{k} \quad$ Kompresör gücü, $\mathrm{kW}$

\section{İndisler}

LTC Düşük sıcaklık çevrimi

HTC Yüksek sıcaklık çevrimi

SYS Tüm sistem çevrimi 


\section{Kovacı, $T$.}

\section{REFERENCES / KAYNAKLAR}

Alhamid, M. I. \& Syaka, D. R. (2010). Exergy and energy analysis of a cascade refrigeration system using R744+ R170 for low temperature applications. International Journal of Mechanical \& Mechatronics Engineering, 10(6), 1-8.

Aminyavari, M., Najafi, B., Shirazi, A. \& Rinaldi, F. (2014). Exergetic, economic and environmental (3E) analyses, and multi-objective optimization of a $\mathrm{CO}_{2} / \mathrm{NH}_{3}$ cascade refrigeration system. Applied Thermal Engineering, 65(1-2), 42-50.

Başaran, A. \& Özgener, L. (2013). Doğaya zararlı halokarbon soğutkanların çevresel etkileri ve alınan önlemler. Engineer \& The Machinery Magazine, 54(640), 45-53.

Boyaghchi, F. A. \& Asgari, S. (2017). A comparative study on exergetic, exergoeconomic and exergoenvironmental assessments of two internal auto-cascade refrigeration cycles. Applied Thermal Engineering, $122,723-737$.

da Silva, A., Bandarra Filho, E. P. \& Antunes, A. H. P. (2012). Comparison of a R744 cascade refrigeration system with R404A and R22 conventional systems for supermarkets. Applied Thermal Engineering, 41, 30-35.

Dopazo, J. A., Fernández-Seara, J., Sieres, J. \& Uhía, F. J. (2009). Theoretical analysis of a $\mathrm{CO}_{2}-\mathrm{NH}_{3}$ cascade refrigeration system for cooling applications at low temperatures. Applied Thermal Engineering, 29(8-9), 15771583.

EES. (2016). Engineering Equation Solver, F-Chart Software.

Khanmohammadi, S., Goodarzi, M., Khanmohammadi, S. \& Ganjehsarabi, H. (2018). Thermoeconomic modeling and multi-objective evolutionary-based optimization of a modified transcritical $\mathrm{CO}_{2}$ refrigeration cycle. Thermal Science and Engineering Progress, 5, 86-96.

Lizarte, R., Palacios-Lorenzo, M. E. \& Marcos, J. D. (2017). Parametric study of a novel organic Rankine cycle combined with a cascade refrigeration cycle (ORC-CRS) using natural refrigerants. Applied Thermal Engineering, $127,378-389$.

Llopis, R., Sánchez, D., Sanz-Kock, C., Cabello, R. \& Torrella, E. (2015). Energy and environmental comparison of two-stage solutions for commercial refrigeration at low temperature: Fluids and systems. Applied Energy, 138, 133-142.

Mancuhan, E., Tunç, B., Yetkin, K. \& Çelik, C. (2019). Comparative analysis of cascade refrigeration systems' performance and enviromental impacts. Journal of the Turkish Chemical Society Section B: Chemical Engineering, 2(2), 97-108.

Messineo, A. (2012). R744-R717 cascade refrigeration system: performance evaluation compared with a HFC two-stage system. Energy Procedia, 14, 56-65.

Mishra, R. S. (2018). Thermodynamic analysis of two stages cascade refrigeration system using r-1234ze in high temperature circuit and r1234yf in low temperature circuit for replacing HFC (R-134a) refrigerant. International Journal of Research in Engineering and Innovation, 2(4), 364-373.

Oruç, V., Devecioğlu, A. G. \& Ender, S. (2018). Improvement of energy parameters using R442A and R453A in a refrigeration system operating with R404A. Applied Thermal Engineering, 129, 243-249.

Parmar, G. G. \& Kapadia, D. R. (2015). Thermodynamic analysis of cascade refrigeration system using a natural refrigerants for supermarket application. International Journal of Innovative Research in Science, Engineering and Technology, 4(6), 1839-1846.

Singh, S. \& Dasgupta, M. S. (2016). Thermodynamic analysis of a low TEWI (R1234yf-R744) cascade system. National Conference on Recent Trends in Mechanical Engineering, India. 
Yilmaz, B., Erdonmez, N., Sevindir, M. K. \& Mancuhan, E. (2014). Thermodynamic analysis and optimization of cascade condensing temperature of a CO2 (R744)/R404A cascade refrigeration system. International Refrigeration and Air Conditioning Conference, ABD.

Y1lmaz, F. \& Selbaş, R. (2017). Energy and exergy analyses of $\mathrm{CO}_{2} / \mathrm{HFE7000} \mathrm{cascade} \mathrm{cooling} \mathrm{system.} \mathrm{Süleyman}$ Demirel Üniversitesi Fen Bilimleri Enstitüsü Dergisi, 21(3), 854-860. 